\title{
An Investigation into Female Students' Less Participation in English Language Class: Waja Kero Junior Primary School Grade 8 Students in Focus
}

\author{
Aynalem Dana \\ Lecturer, College of Social Sciences and Humanities, \\ Department of English Language and Literature, \\ Wolaita Sodo University, Wolaita, Ethiopia
}

\begin{abstract}
The growing interest in gender issues, relationships, family constructs etc can be seen in academia and elsewhere. The power of literary texts, plays, films and dramas in the formation and perception of women's images is immense. These perceptions change with time and ideology. Change in ideology, always mark a paradigm shift in the way we understand and interpret social, economic and political agendas. The introduction of Marxist ideology in a society is an example. Even though Education is most important to pursue the objective of women's empowerment, gender imbalance that prevails at various levels of schooling has been a hampering factor. Besides enrollment, gender disparity manifests in areas of class participation and achievement in primary education institutions. In Ethiopia, even if through several interventions, the enrollment of female students at various levels of schooling has dramatically been increased, questions like in class participation and achievement remain unanswered. This piece of writing, while investigating the issues of representation vs. participation has an objective of assessing why female students' participation in class is low compared to male counterparts. Applying feminist qualitative research, this study identified that shyness, language proficiency, family background, instructor's affiliation to active students, environment, and lack of value attached to participation in class were having impacts on female students participation in class. In contrast, representation in class compared to male counterpart was not a decisive factor. And the researcher concludes that, unless otherwise interventions to enhance females' education in Ethiopia further investigate the issues of in class participation and achievement, the so far efforts have been only tip of the iceberg especially at Waja Kero primary school in rural Ethiopia. Waka Kero primary classroom has been regarded as male public space. This has affected the academic achievement of female students, which in turn is likely to influence negatively their social, economic and political visibilities. As such, females' participation in the classroom activities becomes an inviting topic to be explored. The current study, thereby, aimed to unveil the reasons of highly inhibited and highly exuberant female students in the classroom. In so doing, observations and interviews were carried out on students studying at the primary school of Waja Kero. The findings revealed that inhibition, depreciation of participation, devaluation of speech in mixed environment, and peers' negative comments were the main factors hindering female students' participation. Factors that have been rated as strong promoters of participation, however, were: positive perception of participation, modern thinking, well-rounded knowledge about the topic, the type of topic studied, accessible teachers, and learner-centered approach.
\end{abstract}

Keywords: Wajakero, classroom participation, female students, factors, less participation

DOI: $10.7176 /$ RHSS/10-5-03

Publication date: March $31^{\text {st }} 2020$

\section{Introduction}

A study of Feminist Literary Theory and Criticism cannot be seen separately from the Feminist Movement. The basis and impetus for much of the theoretical foundation for Feminist Theory and Criticism, is the Feminist Movement.

The perception and actual lives of women have been determined by the various media of communications. Literary Text is one of them. It is a powerful tool which produces gender representations at odds with women's experiences. Feminist Literary Theory and Criticism tries to examine this phenomenon. By deconstructing, examining, patriarchal writing and its underlying conceptual framework, feminist literary criticism provides enormous and varied theories and critical analysis.

It has also firmly been believed that because of the existence of gender stereotypes and gender roles, it is difficult to determine whether differences in the behavior of females and males stem from Biological differences between them, or from the self-fulfilling impact of these stereotypes and gender roles. However, most psychologists firmly believe that gender differences arise in large measure from contrasting socialization practices for girls and boys, and from the pervasive influence of gender stereotypes and gender roles (Baron, 2016).

It is also widely assumed that females have higher verbal abilities than males and that male surpass females in mathematics. Do these cognitive differences really exist? While some differences do appear to exist between females and males with respect to various cognitive abilities, such differences are generally smaller than gender 
stereotypes suggest (Baron, 1996).

Furthermore, according to Hassaskhah (2012), being and becoming is the ultimate objective of any educational enterprise, including language teaching. However, research results indicate seemingly unjustified differences between how females and males are treated by EFL teachers.

There are numerous indicators within schools and society that points to the fact that gender bias is present in the curriculum and teachers' practices. Gender bias, according to Sunderland (2005); operate at different levels in English as a Foreign Language (EFL) classrooms: classroom materials, English language itself, and classroom processes that always interact within a particular political, sociolinguistic and educational context. Examples of gender bias are one gender is substantially over- or underrepresented in a curriculum, such as the stereotypical images of men and women present in the textbooks; teacher expectations are related to or affected by student gender; or classroom practices, teaching methods or discipline disproportionately affect one gender (Dabiri, 2006; Fabes et al., 2013; Mehran, 2003; Streitmatter, 2014).

Considering that inequalities in classrooms may wrongly decide who in general is empowered as a learner and unrealistically define who a learner is as a person, gender bias with all its complexity and subtlety has to be recognized and controlled in advance of every aspect of students' classroom life (Streitmatter, 2014). Concerned with the issue, this study aims to reason that students who do not interact with their teachers are less likely to receive encouragement, chance to talk, and hence learn - a threat that is recognized by Sternglanz and LybergerFicek (2017) as influential in determining underrepresentation in postsecondary education.

Whereas many of the earlier studies indicated that gendered classroom interaction could obstruct and even harm knowledge acquisition for males and females (Yepez, 2004), still little is known about how gender bias might affect second language acquisition in adult EFL classrooms, and how teacher's gender might affect teacher-student interaction (Good et al., 1973). In line with this concept, Eskindir (2008) conducted research on female roles and sacrifice in political drama and film, and his research work indicated the females' misrepresentation and stereotyped position in political drama and film. Moreover, Mekonnen Zegeye's MA thesis on 'Images of women and plot structure in the first four novels of Fikre Markos Desta' (June 2001), classifies the women portrayed in two categories, women who were depicted as 'strong and liberated' and women as victims of the patriarchal system. Mekonnen cites other research papers and thesis for his research. Notables are the Askal Lema's 'Images of Feudal Women Characters in seven novels' (2013 E.C.) and Yeshi (2003) 'Images of Women in Pre-revolution plays' $(1978$

EC), where in both works, the women were seen as cruel, shallow, and greedy. Yeshi, concludes that even though the plays did not give a genuine representation of the problems of Ethiopian women at the time, the plays tried to show how the culture was detrimental to women. However, the above mentioned works didn't say something about the positions of the effect of female's less participation in classrooms. Moreover, considering that teachers' expectations of male and female students are subject-sensitive (Duffy et al., 2001), and the other question that arises is whether this "differential teacher treatment by gender" may be manifested in the foreign language classroom, an environment in which females are generally thought to outperform males (Sunderland, 2005). In the light of these questions, the following objectives were postulated for this study:

$>$ To identify the factors that affect female students' participation in English language class?

$>$ To identify possible solutions for the existing problems

$>$ To identify classroom strategies to promote gender equality

\section{Delimitation of study}

This research was delimited to study in Waja Kero primary school grade 8A and factors that affect female students' participation in English language class problems. The school is located in Waja Kero in southern nations nationalities and peoples region in Ethiopia, which is found about 380 kilometers south of Addis Ababa, the capital of Ethiopia. In Waja Kero School, there were 21 classes of grade 1-4 and 34 classes of grade 5-8. Among these, the researcher used only grade 8 students.

\section{Methods}

\subsection{Design of the study}

Research design is a logical sequence that connects empirical data to the study's initial research questions and ultimately to its conclusions (Mertiler, 2005). In order to describe or delineate, analyze and specify naturally occurring phenomena without experimental manipulation, the researcher used descriptive survey method (Seliger and Shohamy, 1989). It was used to establish the existence of phenomenon by explicitly describing them. Moreover, in order to have a clear concept of the nature of the problem, descriptive survey method was employed for this study because it appears suitable for refining research tools, such as questionnaire, classroom observation, focus group discussion, and semi-structured interview. The relevance of this method for such purpose has been confirmed by Best and Kahn, 1998; Mertiler, 2005; and Gall et al. 1996. 


\subsection{Participants and Sampling Technique}

The subjects of the study were school principals, English teachers, parents, grade 8 students, Wereda education officers, and supervisors from the selected school of Wolaita zone enrolled in 2019 academic year. The teachers' profile showed that all the subject teachers have got their BA degree in English; one also has MA in TEFL. They have stayed in the teaching profession for more than twenty years, out of which they taught English at the secondary level for a minimum of fifteen years. Particularly, they have been teaching the new Secondary English course for Grade 8 for the last two to six years.

However, the teachers' responses proved that they have not been given any considerable in-service training since they have left the universities with their degrees. Even when the English syllabuses were revised and the new course books were put into practice, no further strategies were implemented to explain the changes to the teachers and to train them in new techniques. So far, only a one week awareness raising workshop was organized for some representative teachers from each school. But no one could deny that teachers must have both subject knowledge and professional education/training for effective teaching to take place.

In each class, there were about 75-80 students, which could be taken as a very large class size. It is suggested that for descriptive studies, a common recommendation is to sample approximately $10-20 \%$ of the respondents or top achievers of the respondents Barry (2012). In this regard, Twelve English teachers and 92 students of Grade 8 responded to the required data. 32 parent-teacher association members, 4 school principals, 16 woreda education officials, 16 supervisors and 40 focus group discussants were selected using availability sampling from the Waja Kero School. According to Creswell (2012: 145), "In availability sampling (i.e, the researcher selects individuals because they are available, convenient, and represent some characteristic the investigator seeks to study."

\subsection{Data Collection Tools}

So as to collect the required data for the study, three types of instruments: content analysis, questionnaire and classroom observation were used. Researchers such as Cohen and Manion (1994) and Seliger and Shohamy (1989) have proven these instruments to be more productive in generating information on language teaching-learning practices. First, questionnaire was prepared in English and translated into mother tongues, which are the languages of students and their parents in the study areas. Questionnaire is a popular means of collecting all kinds of data in research (Han, 2010; Mertler, Craig, and Charles (2005). Koul ((2005)) further argued that questionnaire is widely used in educational research to obtain information about certain conditions and practices, and to inquire into opinions and attitudes of an individual or a group. To this end, both closed-ended and open ended questions in a Likert scale and YES/NO questionnaire items were used to gather information from the participants. The second data collection tool was interview to obtain deeper information, and it was employed to gather information from school principals, students' parents, English teachers, Wereda education officers and supervisors of the sample schools. In this case, semi-structured interview questions were employed to elicit the feelings of all interviewees who were participated in process of interviewing. In this regard, items translated into mother tongue were administered to parents and those in English were administered to principals, English teachers, Wereda education officers, and supervisors. Focus Group

Discussion (FGD) was also employed so as to depict students' perceptions and opinions about the EFL/ESL teaching learning process freely. Though the suggested size of focus group discussants varies, in this research, a minimum of eight (8) to twelve (12) students were participated. Focus group can reveal a wealth of detailed information and deep insight and allow students to thoughtfully answer questions in their own words and add meaning to their answers. Video-recording was also used to support the data (Michale et al. (2001).

\section{Ethical Issues and Procedures}

In taking into account aforementioned information gathering tools, all possible means were used to communicate with different respondents in the selected school so as to get valid and reliable data. In this regard, positive and cooperative environment were created in the first round contact with all school principals and adjustments were made to achieve getting actual data from desired participants-teachers, students, parents, principals, Wereda education officers and supervisors. Next, with the adjusted time interval, questionnaire was distributed to students; interview was held with parents, English teachers, principals, Wereda education officers and supervisors; focus group discussion was carried out with selected students. They all were informed about the confidentiality of data they had provided. 


\section{Results and Discussions}

Table -1: Students responses based on the problem of students' participation in English class.

\begin{tabular}{|l|l|l|l|}
\hline \multirow{2}{*}{ Items } & Alternatives & $\begin{array}{l}\text { Number } \\
\text { respondent }\end{array}$ & of \\
\hline \multirow{2}{*}{$\begin{array}{l}\text { How often do you practice tasks on participating both } \\
\text { in group and individually to develop independent } \\
\text { learning }\end{array}$} & A/always & 20 & $21.8 \%$ \\
\cline { 2 - 4 } & B/some times & 70 & $76.08 \%$ \\
\cline { 2 - 4 } & C/seldom & - & - \\
\cline { 2 - 4 } & D/never & 2 & $2.17 \%$ \\
\hline Total & & $\mathbf{9 2}$ & $\mathbf{1 0 0 \%}$ \\
\hline
\end{tabular}

As can be seen from table, one $76.08 \%$ the students said that they sometimes practiced in class participation on tasks while $20(21.8 \%)$ and $2(2.17 \%)$ of the students said that they have practiced in participating class always and never respectively. From this can be concluded that most of the students have found practice in participating some times. That is, student should be active since learning is seen as a quest for knowledge. Indeed, one of the manifestations and proves that learning is taking place is the student's engagement in the classroom participation. Participation in the classroom is regarded as exchanges between teacher and students and/or between students and their peers. Rocca (n.d.) contended that such exchanges take three different forms: questions, answers and comments. According to Tatar (2018), active classroom participation contributes quintessentially in the success of education and students' personal development in the future. Furthermore, Astin (2000) found that students, who are actively engaged in the classroom participation, reported higher satisfaction and higher persistence rates.

Despite such importance, the majority of female students are reported to be less active than their male counterparts. Several researchers proposed different factors which influence female student participation in the classroom. For instance, while some studies divided these factors into two main categories: class-related variables such as class-size, and gender distribution and student traits such as social, and religious background Liu(2001), others stated that beside personal and class traits, teacher traits such as gender and course policies can influence female student's participation in the classroom McDonnell(2007).. These disparate arrays of sources and categorizations give the premise that factors which influence female students are not stable traits but are determined by the social, cultural and religious background and context of the subjects.

As such, the current paper seeks to ferret out the factors which exert a crucial influence on Mauritanian female students' participation in the classroom activities.

Table-2: About the students' extent to participate in a classroom

\begin{tabular}{|l|l|l|l|}
\hline Items & Alternatives & Number of respondents & $\%$ \\
\hline \multirow{3}{*}{ Which aspect of English do } & A/Grammar and usage & - & - \\
\cline { 2 - 4 } & B/Vocabulary & 2 & $13.33 \%$ \\
\cline { 2 - 4 } & C/only writing & 78 & $84.8 \%$ \\
\cline { 2 - 4 } & D/listening and speaking & 2 & $13.33 \%$ \\
\hline Total & & 92 & $100 \%$ \\
\hline
\end{tabular}

As can be seen from table two, 11(84.8\%) of the students said that they were more interested and engaged on only in writing but few students $2(13.33 \%)$ and $2(13.33 \%)$ said that they are vocabulary, listening and speaking. From this table the researcher possibly understood that majority of the students are hindering themselves from participating in class.

Table-3: The students learning manner (method)

\begin{tabular}{|l|l|c|l|}
\hline \multicolumn{1}{|c|}{ Items } & Alternatives & Number of respondent & $\mathbf{\%}$ \\
\hline \multirow{2}{*}{$\begin{array}{l}\text { How often do you learn } \\
\text { English language? }\end{array}$} & A/always & 92 & $100 \%$ \\
\cline { 2 - 4 } & B/Some times & - & $26.66 \%$ \\
\cline { 2 - 4 } & C/rarely & - & $33.33 \%$ \\
\cline { 2 - 4 } & D/never & - & $26.66 \%$ \\
\hline Total & & 92 & $100 \%$ \\
\hline
\end{tabular}

It has been argued that English course is compulsory to all Waja Kero Junior primary school and in this regard, they always take the course. However, from observation result, the researcher perceived that majority of classroom tasks were done through the students' mother tongue, which may hinder the students' target language skills.

Table -4: The students getting feedback.

\begin{tabular}{|l|l|l|l|}
\hline Items & Alternatives & Number of respondent & $\%$ \\
\hline \multirow{2}{*}{$\begin{array}{l}\text { How often do you ask your teacher or } \\
\text { another or group member for feedback? }\end{array}$} & A/always & - & - \\
\cline { 2 - 4 } & B/Some times & 2 & $5 \%$ \\
\cline { 2 - 4 } & C/rarely & 10 & $9 \%$ \\
\cline { 2 - 4 } & D/never & 80 & $86 \%$ \\
\hline Total & & 92 & $100 \%$ \\
\hline
\end{tabular}


It may be because of the students' home background that no student dare to ask feedback, whether from their classmates or from their teachers. This behavior is more found to be reflected in females because they fear to ask for feedback or for any comment. The findings of the study emphasize the roles of teachers and students in shaping classroom participation, and confirm that classroom context is a unique social place where many interrelated factors contribute to how and why things happen in class. Furthermore, the findings point out several socio-cultural factors, such as shyness, religion, gender and culture, that influence much of what happens in the class. An interesting finding of this study is expressed by the learners' positive perception of 'shyness', because it is seen as a positive natural feeling that shows a mutual respect of all this study's participants, both male and female. It indicates that shyness is related to different causes, such as the unfamiliarity of the class context, and the expected social and Christianity practices.

\subsection{Family background}

As it was discussed above, males and females grow up in different manner. While some families give complete freedom to male, denying females the equality right within the household, very few may privilege both male and female. Given the culture bounded nature of Ethiopian society, there is a long way to walk to bring gender equality. Changing the so called cultural settings of the community requires radical change in the attitude of men, women, boys and girls. The early child hood experiences of the ways in which males and females have been treated by their families do have a significant impact throughout their schooling life.

Table -5: About the students studying habit

\begin{tabular}{|l|l|l|l|}
\hline Items & Alternatives & Number of respondent & $\%$ \\
\hline \multirow{4}{*}{ How often do you study Vocabulary? } & A/always & - & - \\
\cline { 2 - 4 } & B/some times & - & - \\
\cline { 2 - 4 } & C/rarely & - & - \\
\cline { 2 - 4 } & D/never & 92 & $100 \%$ \\
\hline Total & & $\mathbf{9 2}$ & $\mathbf{1 0 0 \%}$ \\
\hline
\end{tabular}

Well-rounded knowledge about the topic was a recurrent factor in the respondents' answers. They pointed out that they never prepare for the courses because their poor background knowledge do not help them in developing a good understanding of the topic and gives the students the inability to ask many questions and thus check faulty knowledge. As one student put it: "well, maybe if I was high knowledgeable, I would not be reluctant to participate at the same rate or in the same way when I am versed in the topic at hand... I do not want to make superficial observation or give irrelevant information which may lead students to dumb me." They wanted also to contribute to the discussion through sharing their ideas. However, the above table shows negative as all students chose never.

Table -6: Questionnaire item on the students' studying habit

\begin{tabular}{|l|l|l|l|}
\hline \multicolumn{1}{|c|}{ Items } & Alternatives & Number of respondent & $\%$ \\
\hline \multirow{3}{*}{ How is your studying habit? } & A/high & - & - \\
\cline { 2 - 4 } & B/Medium & 85 & $92.39 \%$ \\
\cline { 2 - 4 } & C/Low & 5 & $5.43 \%$ \\
\cline { 2 - 4 } & D/none & 2 & $2.17 \%$ \\
\hline Total & & $\mathbf{9 2}$ & $\mathbf{1 0 0} \%$ \\
\hline
\end{tabular}

Even though there are many factors that may be out of the student control, the students' study habit plays great role in the students' English language improvement and their participation, but as we can see from the above table, majority of the student respondents above, i.e. 85 (92.39\%) reported that they do have medium study habit. Rubin and Thompson (1983) suggest characteristics of 'good' or efficient learners. According to these scholars, 'good' language learners find their own way, organize information about language. They are creative and experiment with language, make their own opportunities and strategies for getting practice in using the language inside and outside the classroom; and learn to live with uncertainty and develop strategies for making sense of the target language without wanting to understand every word (as cited in Nunan, 1991: 171).

Table 7: Teachers' Feedback on the students' participation

\begin{tabular}{|l|l|l|l|}
\hline \multicolumn{1}{|c|}{ Items } & Alternatives & Number of respondent & $\%$ \\
\hline \multirow{2}{*}{$\begin{array}{l}\text { Does your teacher Encourage you in the class to do } \\
\text { more? }\end{array}$} & \multirow{2}{*}{ Yes } & Respondents & $\%$ \\
\cline { 2 - 4 } & No & 42 & $54.34 \%-$ \\
\hline Total & & 92 & $45.7 \%$ \\
\hline
\end{tabular}

Some teachers now see such differences as inevitable and to be built on as a method for raising achievement. For example, they consider that girls and boys as groups have different learning styles, or that as groups they have different preferences for learning materials and content, and play to these differences in teaching practice. Clearly, teachers are all in Ethiopia influenced by socially prevalent views about gender, ethnicity and social class; and we 
use these in part to inform and create our own identities. As can be seen above students' views have been divided into half-half perception.

The perspectives of boys on their experience in school during kindergarten have not been explored in any significant way. Still missing in the literature is critical interpretive research on young, male children's early schooling experiences and the implications for the academic outcomes of these students. There is evidence that some boys do not perform well in secondary school (West, 1999; Coulter, 2003; Martin, 2003) and this is predictable as early as the first year of formal schooling (Barrett, 1989; Alexander et el., 1993; Rimm-Kaufmann \& Pianta, 2000).

Table -8: About the students got equal chance with male to do every activity?

\begin{tabular}{|l|l|l|l|}
\hline Items & Alternatives & Number of respondent & $\%$ \\
\hline \multirow{2}{*}{$\begin{array}{l}\text { Do you always get equal chance with male to } \\
\text { do every activity? }\end{array}$} & & & \\
\cline { 2 - 4 } & Yes & 5 & $5.4 \%$ \\
\cline { 2 - 4 } & No & 87 & $94.56 \%$ \\
\hline Total & & 92 & $100 \%$ \\
\hline
\end{tabular}

Women are conventionally believed to be subordinate and supportive in a mixed-sex conversation, while men are considered to be relatively dominant and competitive. In the school context, gender identity is hugely salient. There has been a traditional assumption that competitive tendencies are much rewarded in the school context and that female students' and male students' classroom participation is not equal, especially the male students are more likely to dominate (Coates, 2004:196). In this regard, the above table on the item which reads, "Do you always get equal chance with male to do every activity?", and majority of the respondents replied that there was no equal chance during every classroom participation, and factors influencing the gender differences in classroom talk may cover four aspects. Firstly, gender identity and social circumstances are of significance in the outcome of young students' academic performance, in particular the classroom participation. Secondly, the interaction patterns in class play a very important role in the students' speaking performance. Thirdly, teacher's conscious intervention on the balance of classroom participation accounts. Finally, the subject as well as the class composition plays a joint role in shaping the situations for girls' and boys' performance. However, the study result replied that both students' and teachers 'scenario at Waja Kero Junior Primary School reflect negative on the female students 'equal participation English as a foreign language classroom. The researcher's observation also showed that the students' religious background also played its own great role in hindering the students' confidence in language classroom in that students, as if they are ordered by their religious fathers, keep silent and feel shy of using English a foreign language.

\subsection{Class Observation}

The teachers in Class 1 and Class 2 obviously have an idea to provide equal opportunities for each student to speak in class. They make good use of various teaching methods or strategies to motivate every student to speak more or read more in English, for example, the activity like argumentative speech in group, group discussions which are used to increase understanding of the material, as well as group presentations, in order to encourage second language learners to practice the target language as much as possible and to ensure equality in the classroom participation. Cooperativeness is much rewarded in the class interaction, for instance, team-work and contributions of each member are desirable and valuable in the group discussion and presentation, which helps to construct a less threatening but advantageous context for girls to speak.

Changes have taken place with the teachers' conscious intervention on the balance of the contributions made by each group. The findings in Class 1 indicate that girls enjoy an advantageous speaking environment in English class. Boys, on the other hand, still have an equal share of classroom talk. Both sides are benefited from the class interactions. The findings in Class 2 obviously show an opposing wind to male dominating world that it is young female speakers that dominate the class. Teacher's role in distributing the turns is relatively preferable to girls since she thinks that girls may shy to speak up. This may be because of the teacher's personal intervention to motivate female students while other rural Ethiopian female dominated classes even keep silent in English classrooms.

Generally speaking, some strategies the teachers have adopted to ensure the girl students get an equal share of the classroom talk. When they direct or organize activities, they tend to select topics of interest to girls which will encourage them to contribute more to the discussion. Small group discussions and group presentations are often used not only as a preparation for a whole classroom discussion of issues, but as an effective way of cooperation, so that the girl students are encouraged to talk more and to play an active role in a less threatening but advantageous context.

\subsection{Analysis of teachers' interview questions.}

In recent years, policy-makers in Ethiopia have called for measures to increase female recruitment to the teaching profession, particularly to consolidate female students' classroom participation because male teachers are found 
threatening female students asking for sex and other harassments. This policy of targeted recruitment is predicated upon a number of unexamined assumptions about the benefits of matching teachers and pupils by gender. For example, it is held that the dearth of female 'role models' in schools continues to have an adverse effect on females' academic motivation and engagement. Utilizing data from interviews with more than 50 youths attending primary schools in the rural Ethiopia, especially at Waja Kero, which is found in South Ethiopia, the paper sets out to scrutinize these claims. The findings revealed that the gender of teachers had apparent effect on the academic motivation and engagement of either boys or girls. For the majority of the children, the gender of the teacher was largely important. They valued teachers, whether men or women, who were consistent and even-handed and supportive of them as learners.

According to reports sponsored by government and non-governments organizations, girls receive significantly less attention from teachers than boys do. This is due in part to the fact that, in general, boys are more likely to call out answers to questions posed to the class even if they haven't been called on by the teacher. This trend may also exist because boys are often perceived as being more mischievous, causing teachers to monitor and engage with them more actively in class, giving a perceived 'opening' to speak without permission. For example, boys are often praised more than girls for sharing correct knowledge, and wrong answers provided by boys are likely to be overlooked. In contrast, girls are more often criticized for conveying incorrect knowledge, and teachers tend to provide less praise for correct answers given by girls. As with the lack of publicity in teachers' conversations with girls, this makes knowledge provided by girls less visible. From this, an expectation arises that boys' knowledge is more highly valued than that of girls, which can convince girls that they are less competent than boys.

\section{Conclusions}

In conclusion, the researcher has been investigating why female student's participation in EFL class is low compared to male counterparts. The study was done on female students at Waja Kero junior primary school. Continued experience of the teacher has laid a ground for commence of the investigation and the study was a comparative nature. A lot of investigations in areas of gender and education worldwide dictate that there is gender imbalance at every stage of schooling and the same is true in Ethiopia. Ethiopia is a culture bound society where the patriarchal social setting occupies a significant place. As patriarchal society glorifies the rule of men and relegates the values attached to women to secondary, women's pivotal role in the socio political setting of the nation remains unrecognized. Unlike the earlier periods, the contemporary government has a vision to bring gender equality in all social, political and economical spheres through continued and devoted females' education. But a lot of things remain under interrogation as regards female education in Ethiopia as majority of interventions has not yet been targeted towards identifying differentials in areas of in class participation and achievement. The researcher believes that unless these critical questions got a precise response, the efforts to bring gender equality in education in Ethiopia so far are only tip of the iceberg.

\section{Reference}

Askal Lema (2013). “Gender Differences in EFL Learning Styles: A Case of Two Preparatory Schools.” MA Thesis (Unpublished): Addis Ababa University.

Astin, A. W. (2000). Student Involvement: A Developmental Theory for Higher Education. Journal of College Student Development, 40, 518-529.

Baron, K. (2016). Understanding Second Language Acquisition. Oxford: Oxford University Press.

Barry, V. (2012). Establishing Self- Access from Theory to Practice. Cambridge: Cambridge University Press. Best, J.W. and Khan, J.V. (1998).Research in Education ( $7^{\text {th }} \mathbf{e d}$.). New Delhi:Prentice-Hall of India Private Ltd. Creswell, W. (2012). Psychology for Language Teachers: a Social Constructivist Approach. Cambridge: Cambridge University Press.

Creswell, J. (2009). Qualitative Inquiry and Research Design. Sage, Thousands Oak, CA.

Cohen, L., Manion, L., Morrison, K. \& Morrison, K. R. B. 1994. Research methods in education, Psychology Press.

Duffy, N. (2001). The social context for language learning: A neglected situation. Studies in second language acquisition. 7(2), pp.135-158.

Eskindir Hailu (2008). Feminist Theory From Margin to Center. Cambridge: Sound End Press.

Fabes, M. Pahlke,R. Martin, D. and Hanish,L. (2012). Images of women in Ethiopian plays. Master thesis,Literature. Addis Ababa University.

Hassashhah, H. (2012). Toward a Feminist Theory of the State. Cambridge: Harvard University Press.

Koul, L. (2005). Methodology of Educational Research ( $3^{\text {rd Revised }}$ Ed.). New Delhi: Vishal Printers.

Michale,L. Jane,J. Michelle, U. \& Kate, B. (2001). Success in diversity: culture, knowledge and learning in ethnically diverse primary classrooms. Thesis, Goldsmiths College (University of London).

Mehran, G. (2003). Gender in the college classroom: An assessment of the "chilly climate" for women. Sex Roles. 
23 (3-4), pp.101-122.

Mekonnen Zegeye. (2001). Images of women and plot structure in the first four novels of Fikre Markos Desta. Masters thesis, Literature. Addis Ababa University

Mertler, C.A. and Charles, C.M. (2005). Introduction to Educational Research $\left(5^{\text {th }}\right.$ Ed.). New York: Pearson Education, Inc.

Rocca, K. (2010). Student Participation in the College Classroom: An Extended Multidisciplinary Literature Review. Communication Education, 59, 185-213.

Streitmatter J.( 2014). Toward gender equity in the classroom: Everyday teachers' beliefs and practices. Albany: State University of New York Press.

Sternglanz, \& Lyberger-Ficek, (2017). Investigating teacher's classroom management based on students' gender]. Modern Educational Notions, 2, 43-69.

Sunderland, J. 2005. “Classroom Interaction, Gender and Foreign Language Learning.” In

Norton, B. and K. Toohey (ed.): Critical Pedagogies and Language learning. Pp. 222-241.Dibiri, 2006

Yepez, E. 2004. "An Observation of Gender-Specific Teacher Behaviour in the ESL Classroom -

English as Second Language." Sex Roles. A Joumal 01 Research 30:1,2 (1994): 121133. >www.findarticIes.com/p/articles/mün2294/.

Yeshi Tadesse. (1978 E.C). Images of women in pre-revolution plays. Masters thesis, Literature. Addis Ababa University

Seliger,H.W.andShohamy,E.(1989). Second Language Research Methods. Oxford: UP.

Han, A. (2010). The second gender. US: Vintage books.

Tahar, G. 2018 "Sex Differences in Self Reported Beliefs about Foreign language learning and Authentic Oral and Written Input.” Language Learning, Vol. 42, No. 4, Pp. 471 - 495.

Liu, D. 2001. "EFL Proficiency, Gender and Language Learning Strategy Use Among a Group of Chinese Technological Institute English Majors." ARECLS E-Journal, Vol.1, A5./http: //www. Ecls.nel.ac.k/publish/volume1/Dongyue/Dongyue htm/

McDonnell, L. (2007). Gender Bias in the College Algebra Classroom? Arizona: University of Arizona Press.

Rubin and Thompson Coultler (2003). Approaches and Methods in Language Teaching: A Description and analysis. Cambridge: Cambridge University Press.

Martin, C. (2003). Interactive Language Teaching. New York: Cambridge University Press.

Barrett, Z. (1989). Principles of Course Design for Language Learners. Cambridge: Cambridge University Press.

Alexander, C. DeLano, L., L. Riley and G.Crookes. (1994). "The meaning of innovation for ESL teachers." System 22/4: 487-496.1993

Rim-Kaufmann and Pianta (2000). "Theoretical bases of communicative approaches to second language teaching and testing." Applied Linguistics 1/1: 1-47.

Nunan, D. 1991. Language Teaching Methodology: a Text Book for Teachers. Great Britain: International Book Distributors, Ltd.West 1999

Coates, Jennifer. 2004. Women, Men and Language (Third Ed.). Harlow: Pearson Education Ltd.

Nunan, D. 1991. Language Teaching Methodology: a Text Book for Teachers. Great Britain: International Book Distributors, Ltd. 